\title{
Consequences of COVID-19 Lockdown on the Misuse and Marketing of Addictive Substances and New Psychoactive Substances
}

\author{
Annagiulia Di Trana ${ }^{1 *}$, Jeremy Carlier ${ }^{1,2}$, Paolo Berretta ${ }^{3}$, Simona Zaami ${ }^{2 \dagger}$ and \\ Giovanna Ricci ${ }^{4+}$
}

${ }^{1}$ Unit of Forensic Toxicology, Section of Legal Medicine, Department of Excellence of Biomedical Sciences and Public Health, Polytechnic University of Marche, Ancona, Italy, ${ }^{2}$ Unit of Forensic Toxicology, Section of Legal Medicine, Department of Anatomical, Histological, Forensic, and Orthopedic Sciences, Sapienza University of Rome, Rome, Italy, ${ }^{3}$ National Centre on Addiction and Doping, National Institute of Health, Rome, Italy, ${ }^{4}$ Medico Legal Section, School of Law, University of Camerino, Macerata, Italy

Keywords: New Psychoactive Substances, social isolation, COVID-19, SARS-CoV-2, early warning advisory systems, socio-economic crisis

OPEN ACCESS

Edited by:

Ornella Corazza,

University of Hertfordshire

United Kingdom

Reviewed by:

Amira Guirguis,

Swansea University, United Kingdom

Attilio Negri,

University of Milan, Italy

*Correspondence:

Annagiulia Di Trana

a.ditrana@pm.univpm.it

†These authors have contributed equally to this work

Specialty section:

This article was submitted to Addictive Disorders,

a section of the journal

Frontiers in Psychiatry

Received: 17 July 2020 Accepted: 28 September 2020 Published: 23 October 2020

Citation:

Di Trana A, Carlier J, Berretta P, Zaami S and Ricci G (2020) Consequences of COVID-19

Lockdown on the Misuse and Marketing of Addictive Substances and New Psychoactive Substances.

Front. Psychiatry 11:584462.

doi: 10.3389/fpsyt.2020.584462

\section{INTRODUCTION}

Since the first outbreak of SARS-CoV-2 (severe acute respiratory syndrome-coronavirus-2) in China in December 2019, the infection has rapidly spread all over the world. This new virus has caused many cases of Coronavirus disease 2019 (COVID-19), a potentially fatal respiratory syndrome (1). Due to its global diffusion, the World Health Organization rapidly issued an international warning and declared a worldwide pandemic in March 2020. Currently, most countries are experiencing COVID-19 outbreaks with new infections and fatalities every day and all over the world (2). Due to the mode of transmission of the virus via droplets or direct contact, governments were compelled to adopt restrictive strategies to contain the pandemic and preserve the public health $(2,3)$. These interventions include limited international mobility, temporary closure of non-essential businesses and more stringent measures like social distancing or complete isolation for prolonged periods. Therefore, this unprecedented crisis has seriously impacted the global economy and people's daily life.

The market of addictive substances has been impacted from the production to the distribution, modifying consumption patterns. An increased consumption of cannabis products and benzodiazepines was reported due to the general feeling of stress caused by the pandemic and associated restrictions, while a decrease in the demand of stimulants was observed due to the inaccessibility of usual recreational settings (4). Moreover, drug misuse may have shifted toward alternative substances and home-made New Psychoactive Substances (NPS) (5-7), which consist of molecules, like pharmaceutical drug analogs, research chemicals and prescription drugs eliciting the psychoactive effects of common illicit addictive drugs or prescription pharmaceuticals $(8,9)$. The current situation is complex due to the heterogeneity of policies applied in diverse countries and the drugs involved. In this concern, the drug market is constantly monitored by international agencies, such as the United Nation Office on Drug and Crime (UNODC), the European Monitoring Centre on Drugs and Drug Addiction (EMCDDA) and Europol, which collaborate to form a crucial network to prevent the emergence of new dangerous trends.

In this article, the authors critically discuss the most recent data on the impact of COVID-19 on the illicit trafficking of substances and the possible developments of NPS trends in the near future. The authors also draw the attention on the essential role of international networking against drug misuse, especially in times of global crisis. 


\section{IMPACT OF INTERNATIONAL RESTRICTIONS ON DRUG PRODUCTION, TRADE AND MARKET}

The anti-COVID-19 restrictive measures have impacted the drug production in a different manner depending on the substance.

The cultivation of natural drugs is usually conducted in different regions of the world during different periods of the year, depending on the climate. Accounting for $84 \%$ of the world production, Afghanistan is the main producer of opium in the Golden Crescent, where poppy is usually harvested between March and June (10). However, the travel restrictions adopted this year have impeded the recruitment of poppy lancers from other regions, and the workforce shortage slowed down harvesting, leading to a partial loss of the production (5). In other countries such as Myanmar, opium harvesting was completed but a decrease in the number of customers was reported (10). Furthermore, the closure of Myanmar borders may have affected the import of acetic anhydride, impacting the production of heroin. Meanwhile, other factors have affected the cultivation of cocaine, which is mainly conducted in Colombia $(70 \%$ of the global cultivation), Peru (20\%), and Bolivia (10\%) (10). Since coca leaves can be harvested throughout the year, the antiCOVID-19 measures have not impacted harvesting in those countries. However, the law enforcement pressure hike during the COVID-19 pandemic and the shortage of essential chemical precursors, such as permanganate salts, and gasoline resulted in the reduction of the production of cocaine, especially in Colombia (5). To date, the production of cocaine seems to be less affected in Peru, but the price reductions suggest that large quantities of drugs were stockpiled (5). Since cannabis products are often locally produced and distributed through short supply chains, the production and distribution of cannabis has not suffered due to the global restrictions $(5,6,11)$.

A different pattern was observed for synthetic drugs, whose production is less related to the geographical location, and probably because clandestine manufacturing laboratories need less workforce. Amphetamine-type stimulants [i.e., methamphetamine, amphetamine and methylenedioxymethamphetamine (MDMA)] are the most commonly used synthetic drugs, and the bulk production is concentrated in few countries only. According to recent data, laboratories manufacturing synthetic drugs are mainly located in North America (84\%), followed by Europe and Asia (10). It is noteworthy that the production of synthetic drugs strictly depends on the availability of chemicals, usually imported from China. Therefore, international travel restrictions and the disruption of raw material production may pose a problem. In fact, a decrease in the availability of synthetic drugs was reported in various countries (e.g., amphetamine in Czech Republic, Lebanon and Syria, and fentanyl and methamphetamine in Mexico) $(5,6)$.

Drug availability also depends on trafficking routes. The complete interruption of air traffic especially affected the export of synthetic drugs from South East Asia and Oceania. Cocaine trade was less impacted by air travel disruption, due to the use of the maritime route $(5,6)$. Furthermore, cocaine export from South America is usually conducted by yacht and other modified boats. Air trafficking may have been replaced by postal distribution, wherever it is possible. Maritime trafficking may also have been preferred to bypass COVID-19-related land controls. In this concern, South-Eastern Asian heroin trafficking has shifted from land to maritime transportation across the Indian Ocean. The highest impact of the global trade disruption is expected for the substances that are usually transported along with licit goods, such as heroin and synthetic drugs $(5,10)$. In recent years, specialized websites have appeared on the darknet as an alternative way to obtain illegal products. Even though several markets have closed since 2018, the darknet still plays a key role in the worldwide diffusion of NPS $(6,12,13)$. Although the drugs found on the darknet represent $0.2 \%$ of the retail sales in western countries, a sharp increase of the darknet drug trade was reported in Europe during the first 3 months of $2020(10,11)$. According to a preliminary study, cannabis-related products are the most sold merchandises through specialized darknet websites in Europe $(6,11)$.

As a result, the drug market has been affected differently at retail and bulk levels. A shortage of several types of drugs and a reduction of their purity was reported in many countries. For example, heroin completely disappeared from street markets in Czech Republic. Conversely, bulk distribution appeared more heterogeneous, with a decrease in seizures in several countries including Italy, Niger, and Central Asia, but an increase in other countries such as Iran and Morocco $(5,6,10)$. However, this discrepancy may depend on the local anti-Covid-19 restrictions and the difference in commitment to enforce these restrictions.

\section{DISCUSSION}

During this year, the SARS-CoV-2 pandemic has posed various challenges to the population. Fear, stress, and anxiety have affected people all over the world, exacerbating latent psychiatric and psychological disorders (14). Furthermore, the general feeling of uncertainty is fueled by the probable economic crisis that will result from the disruption of non-essential businesses in most countries (15). Fragile categories such as people with drug use disorder suffer from the life-style changes, posing additional public health concerns (16).

Besides, the anti-COVID-19 restrictive measures modified the drug offer and altered substance misuse patterns. Drug-related phenomena like the drugs-and driving and drug parties are expected to decrease $(17,18)$. Due to high addiction liability, we suppose that the global shortage of heroin may have forced regular users to take other substances with similar effects, such as fentanyl analogs. Moreover, the low quantity of heroin available may have been adulterated with other psychotropic molecules to obtain more potent mixtures at cheaper costs $(7,19)$. In our opinion, the production of new NPS and NPS use are also expected to increase due to several factors. Firstly, the disruption of the marketing of specific chemical precursors may have forced drug manufacturers to find alternatives, as observed with "Sisa," a drug that emerged onto the Greek market during 
the economic crisis of 2010 (20). Secondly, the decrease in the importation of chemical precursors may have favored the domestic manufacture of domestic precursors, as observed with mephedrone in Russia (10). Another important factor to consider is the increase of law enforcement controls that are not suited for the detection of new uncontrolled molecules. Recently, the intentional misuse of prescription drugs to induce psychotropic effects has spread among people with substance use disorder. The most common misused molecules include gabapentinoids, fentanyl analogs, approved antipsychotics, antidepressants and performance-enhancing drugs (21). For this reason, the diversion of prescription drugs like benzodiazepines, opioids and cognitive enhancers is expected to increase due to higher availability (2224).

Local governments should implement effective measure to prevent those trends that could worsen the state of public health systems. As suggested by Zaami et al., the continuation of drug treatment services along with the implementation of psychiatric and psychological assistance to people with drug use disorder should be ensured to reduce harm (16). To date, a constructive international network is continuously working to monitor the drug market $(15,16)$.

Since its establishment in 2007, the UNODC combats drug misuse and illicit trafficking through research, guidance and support to governments (25). Common international treaties such as The Single Convention on Narcotic Drugs of 1961 and the Convention on Psychotropic Substances of 1971 were issued by the UNODC and are regularly incremented. Following the emergence of the alarming phenomenon of NPS, the UNODC Early Warning Advisory (EWA) was launched in 2013. The first aim of EWA is to monitor, analyze and report the trends of psychotropic substances that are not included in the above-mentioned international conventions (26). The base of the successful work of the UNODC EWA is the tight collaboration with national and regional agencies and governmental entities (26).

\section{REFERENCES}

1. Pesaresi M, Pirani F, Tagliabracci A, Valsecchi M, Procopio AD, Busardò FP, Graciotti L. SARS-CoV-2 identification in lungs, heart and kidney specimens by transmission and scanning electron microscopy. Eur Rev Med Pharmacol Sci. (2020) 24:5186-8. doi: 10.26355/eurrev_202005_21217

2. World Health Organization. Coronavirus Disease (COVID19). (2020). Available online at: https://www.who. int/emergencies/diseases/novel-coronavirus-2019?gclid= CjwKCAjwr7X4BRA4EiwAUXjbt6kz07Hpde18ZRe5xKx0xI00_vBiCjbDAE-y5PpM-ILWoGBYM0qfBoCS7gQAvD_BwE (accessed July 14, 2020).

3. Lai CC, Shih TP, Ko WC, Tang HJ, Hsueh PR. Severe acute respiratory syndrome coronavirus 2 (SARS-CoV-2) and coronavirus disease-2019 (COVID-19): the epidemic and the challenges. Int J Antimicrob Agents. (2020) 55:105924. doi: 10.1016/j.ijantimicag.2020.105924

4. GDS. Global Drug Survey on COVID-19. (2020). Available online at: https:// www.globaldrugsurvey.com/wp-content/themes/globaldrugsurvey/assets/ GDS_COVID-19-GLOBAL_Interim_Report-2020.pdf (accessed September $3,2020)$.
The EMCDDA is a partner of UNODC EWA and coordinates the European network against NPS. In 1997, the Early Warning System (EWS) was implemented under Joint Action 97/396/JHA as a response to the growing NPS concern (27). To EWS is based on a multidisciplinary network comprising several agencies, such as EMCDDA, Europol, the European Medicines Agency (EMA) and 30 national early warning systems. Each national agency operates according to the most recent Regulation (EU) 2017/2101 that establishes a common risk-assessment procedure and a shared three-step approach to respond to NPS (27). In this framework, EMCDDA collects and analyzes national data on NPS emergences, seizures and poisonings to compile a biannual report. Data are also shared with UNODC for a more comprehensive analysis. The European national systems are independent and each state is responsible for its functioning. In Italy, the National Early Warning System (SNAP) on NPS is managed by the National Centre on Addiction and Doping of National Institute of Health (ISS). In this concern, an online platform was developed to allow collaborating centers to spread across the territory to promptly transmit NPS-related information. In addition, EMCDDA data on NPS are reported to SNAP to ensure information sharing between European countries (28).

This capillary network has proved necessary to constantly monitor the new trends of the NPS erratic market. However, many of the current tools for monitoring drug issues at national and international levels are old and may be not effective to capture the complexity of the new drug market. In this concern, the international community should implement more powerful instruments to preserve public health, especially in critical situations such as the COVID-19 pandemic.

\section{AUTHOR CONTRIBUTIONS}

All authors equally contributed to the conceptualization, preparation, and revision of the paper.
5. UNODC-United Nations Office on Drugs and Crime. COVID-19 and the Drug Supply Chain: From Production and Trafficking to Use. (2020). Available online at: https://www.unodc.org/documents/data-and-analysis/ covid/Covid-19-and-drug-supply-chain-Mai2020.pdf (accessed July 27, 2020).

6. European Monitoring Centre for Drugs and Drug Addiction and Europol. EU Drug Markets: Impact of COVID-19. (2020). Available online at: https:// www.emcdda.europa.eu/publications/joint-publications/eu-drug-marketsimpact-of-covid-19_en (accessed July 14, 2020).

7. EMCDDA. Trendspotter Briefing I Impact of COVID-19 on Patterns of Drug Use and Drug-Related Harms in Europe 2. Available online at: https://wdr. unodc.org/wdr2020/field/WDR20_Booklet_3.pdf (accessed July 14, 2020).

8. Zaami S. New psychoactive substances: concerted efforts and common legislative answers for stemming a growing health hazard. Eur Rev Med Pharmacol Sci. (2019) 23:9681-90. doi: 10.26355/eurrev_201911_ 19529

9. Kyriakou C, Pellegrini M, García-Algar O, Marinelli E, Zaami S. Recent trends in analytical methods to determine new psychoactive substances in hair. Curr Neuropharmacol. (2016) 15:663-81. doi: 10.2174/1570159X15666161111112545 
10. UNODC. World Drug Report 2020-Drug Supply. (2020). Available online at: https://wdr.unodc.org/wdr2020/field/WDR20_Booklet_3.pdf (accessed July 27, 2020).

11. European Monitoring Centre for Drugs and Drug Addiction. COVID-19 and Drugs: Drug Supply via Darknet Markets: EMCDDA Special Report. Lisbon: EMCDDA (2020).

12. Jurásek B, Cmelo I, Svoboda J, Cejka J, Svozil D, Kuchar M. New psychoactive substances on dark web markets: from deal solicitation to forensic analysis of purchased substances. Drug Test Anal. (2020). doi: 10.1002/dta.2901. [Epub ahead of print].

13. Wadsworth E, Drummond C, Deluca P. The dynamic environment of crypto markets: the lifespan of new psychoactive substances (NPS) and vendors selling NPS. Brain Sci. (2018) 8:46 doi: 10.3390/brainsci8030046

14. Columb D, Hussain R, O'Gara C. Addiction psychiatry and COVID-19: impact on patients and service provision. Ir J Psychol Med. (2020) 21:15. doi: 10.1017/ipm.2020.47

15. Chiappini S, Guirguis A, John A, Corkery JM, Schifano F. COVID-19: the hidden impact on mental health and drug addiction. Front Psychiatry. (2020) 11:767. doi: 10.3389/fpsyt.2020.00767

16. Zaami S, Marinelli E, Varì MR. New trends of substance abuse during COVID-19 pandemic: an international perspective. Front Psychiatry. (2020) 11:700. doi: 10.3389/fpsyt.2020.00700

17. Gentili S, Mortali C, Mastrobattista L, Berretta P, Zaami S. Determination of different recreational drugs in sweat by headspace solid-phase microextraction gas chromatography mass spectrometry (HS-SPME GC/MS): application to drugged drivers. J Pharm Biomed Anal. (2016) 129:282-7. doi: 10.1016/j.jpba.2016.07.018

18. Parekh V. Psychoactive drugs and driving. Aust Prescr. (2019) 42:1825. doi: 10.18773/austprescr.2019.070

19. Solimini R, Rotolo MC, Pellegrini M, Minutillo A, Pacifici $\mathrm{R}$, Busardò FP, et al. Adulteration practices of psychoactive illicit drugs: an updated review. Curr Pharm Biotechnol. (2017) 18:524-30. doi: 10.2174/1389201018666170710184531

20. Papoutsis IAS. Emergency issues of clandestine production of drugs: the case of "Sisa" - the homemade crystal meth in Greece. J Forensic Toxicol Pharmacol. (2014) 3:2. doi: 10.4172/2325-9841.1000118

21. Schifano F, Chiappini S, Corkery JM, Guirguis A. Abuse of prescription drugs in the context of novel psychoactive substances (NPS): a systematic review. Brain Sci. (2018) 8:73 doi: 10.3390/brainsci8040073
22. Paolo Busardò F, Kyriakou C, Cipolloni L, Zaami S, Frati P. From clinical application to cognitive enhancement: the example of methylphenidate. Curr Neuropharmacol. (2016) 14:17-27. doi: 10.2174/1570159X13666150407225902

23. Schifano F, Chiappini S, Corkery JM, Guirguis A. Assessing the 2004-2018 fentanyl misusing issues reported to an international range of adverse reporting systems. Front Pharmacol. (2019) 10:46. doi: 10.3389/fphar.2019.00046

24. Lapeyre-Mestre M, Boucher A, Daveluy A, Gibaja V, Jouanjus $\mathrm{E}$, Mallaret $\mathrm{M}$, et al. Addictovigilance contribution during COVID-19 epidemic and lockdown in France. Therapies. (2020) 75:343-54. doi: 10.1016/j.therap.2020.06.006

25. UNODC. Early Warning Advisory on New Psychoactive Substances. What are NPS? (2019). Available online at: https://www.unodc.org/LSS/Page/NPS (accessed July 7, 2019).

26. UNODC. Early Warning Advisory System. (2020). Available online at: https://www.unodc.org/unodc/en/scientists/ewa.html (accessed June 19, 2020).

27. European Parliament. REGULATION (EU) 2017/2101 of 15 November 2017Amending Regulation (EC) No 1920/2006 as Regards Information Exchange on, and an Early Warning System and Risk Assessment Procedure for, New Psychoactive Substances. Brussels: European Union (2017).

28. SNAP. Sistema Nazionale di Allerta Precoce contro la droga - ISS Osservatorio Fumo, Alcol e Droga. (2020). Available online at: https:// iss-ofad.azurewebsites.net/2019/07/04/snap-sistema-nazionale-di-allertaprecoce-contro-la-droga/ (accessed July 16, 2020).

Conflict of Interest: The authors declare that the research was conducted in the absence of any commercial or financial relationships that could be construed as a potential conflict of interest.

Copyright (C) 2020 Di Trana, Carlier, Berretta, Zaami and Ricci. This is an open-access article distributed under the terms of the Creative Commons Attribution License (CC BY). The use, distribution or reproduction in other forums is permitted, provided the original author(s) and the copyright owner(s) are credited and that the original publication in this journal is cited, in accordance with accepted academic practice. No use, distribution or reproduction is permitted which does not comply with these terms. 